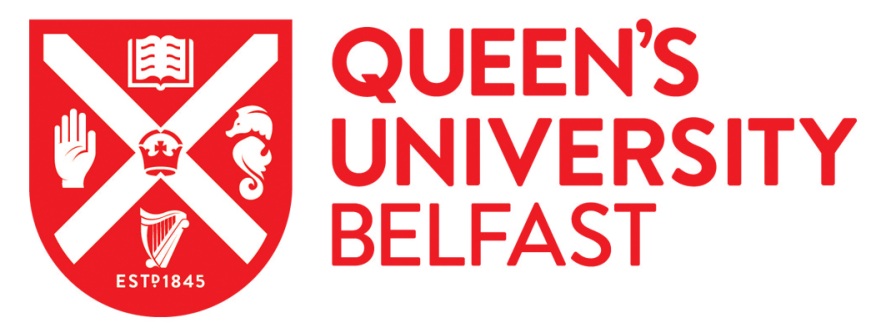

\title{
Ultrasound in undergraduate medical education: a systematic and critical review
}

Feilchenfeld, Z., Dornan, T., Whitehead, C., \& Kuper, A. (2017). Ultrasound in undergraduate medical education: a systematic and critical review. Medical Education.

\author{
Published in: \\ Medical Education
}

Document Version:

Peer reviewed version

Queen's University Belfast - Research Portal:

Link to publication record in Queen's University Belfast Research Portal

\begin{abstract}
Publisher rights
(c) 2016 John Wiley \& Sons and The Association for the Study of Medical Education.

This is the peer reviewed version of the following article: Feilchenfeld, Z., Dornan, T., Whitehead, C. and Kuper, A. (2017), Ultrasound in undergraduate medical education: a systematic and critical review. Medical Education, which has been published in final form at http://onlinelibrary.wiley.com/wol1/doi/10.1111/medu.13211/full This article may be used for non-commercial purposes in accordance with Wiley Terms and Conditions for Self-Archiving.

\section{General rights}

Copyright for the publications made accessible via the Queen's University Belfast Research Portal is retained by the author(s) and / or other copyright owners and it is a condition of accessing these publications that users recognise and abide by the legal requirements associated with these rights.
\end{abstract}

Take down policy

The Research Portal is Queen's institutional repository that provides access to Queen's research output. Every effort has been made to ensure that content in the Research Portal does not infringe any person's rights, or applicable UK laws. If you discover content in the Research Portal that you believe breaches copyright or violates any law, please contact openaccess@qub.ac.uk. 


\title{
Ultrasound in undergraduate medical education: A systematic and critical review
}

\begin{abstract}
Introduction

Point-of-care ultrasound (POCUS) use in clinical care is growing rapidly, and advocates have recently proposed the integration of ultrasound into undergraduate medical education (UME). The evidentiary basis for this integration has not been evaluated critically or systematically. In this study, we conducted a critical and systematic review framed by the rationales enumerated by advocates of ultrasound in UME in academic publications.

Methods
\end{abstract}

This research was conducted in two phases. First, the dominant discursive rationales for the integration of ultrasound in UME were identified using techniques from Foucauldian critical discourse analysis (CDA) from an archive of 403 academic publications. We then sought empirical evidence in support of theses rationales, using a critical synthesis methodology also adapted from CDA.

Results

We identified four dominant discursive rationales, with different levels of evidentiary support. Ultrasound was not demonstrated to improve students' understanding of 
anatomy. The benefit of ultrasound in teaching physical examination was inconsistent, and rests on minimal evidence. With POCUS, students' diagnostic accuracy was improved for certain pathologies, but findings were inconsistent for others. Finally, the rationale that ultrasound training in UME will improve quality of patient care was difficult to evaluate.

\section{Discussion}

Our analysis has shown that the frequently repeated rationales for the integration of ultrasound in UME are not supported by a sufficient base of empirical research. The repetition of these dominant discursive rationales in academic publications legitimizes them and may preclude further primary research. Since the value of clinical ultrasound use by medical students remains unproven, educators must consider whether the associated financial and temporal costs are justified or whether more research is required.

Introduction

Advocates of point-of-care ultrasound (POCUS) propose the integration of ultrasound into undergraduate medical education (UME), driven by a belief "that expanded training in the use of ultrasound will lead to better health care for both individuals and populations" ${ }^{1}$. With the expectation that POCUS will be viewed by future physicians "as an extension of their senses, just as many generations have viewed the stethoscope", 
educators are encouraged to "embrace and incorporate the technology throughout the curriculum" ${ }^{2}$. Some institutions have begun to do just that ${ }^{3-5}$.

The use of POCUS in clinical care has expanded across medical specialties in recent years ${ }^{6}$. There is evidence to support the improved safety of certain procedures with POCUS ${ }^{7-}$ ${ }^{9}$. POCUS has also been shown to assist with certain diagnoses at the bedside, and can rapidly and accurately identify anatomic pathology ${ }^{10-13}$. However, there remains a lack of sufficient evidence to support any clear clinical benefit of even the longest-studied diagnostic application of POCUS (i.e. the FAST examination in blunt abdominal trauma) ${ }^{14}$. Kim et al. ${ }^{15}$ question the "uncritical acceptance" of the diagnostic role of POCUS, which they believe is "spurred by enthusiasm, not science".

It is this environment of proliferating POCUS use, with an evolving evidence base for different applications, in which advocates have promoted incorporation of ultrasound training into the curricula of medical schools. Curricular changes might best be judged on their ability to influence patient outcomes, but because it is difficult to demonstrate how educational interventions achieve these outcomes, such studies are rare ${ }^{16-18}$. Educators are left to weigh other sources of evidence when choosing to implement curricular changes. 
There exists no clear evidence of improved patient outcomes as a result of incorporating ultrasound in UME. Several rationales are suggested by proponents; for example, in a recent article, educators in California suggested four main justifications:

“(1) it can enhance traditional learning; (2) it can train future physicians to improve their diagnostic and procedural skills; (3) it can promote coordinated and efficient patient care; and (4) it can serve as a template for advanced, specialty-specific, or interdisciplinary ultrasound training in graduate medical education and continuing medical education." ${ }^{19}$

Two reviews have been published on ultrasound in UME. Mircea et al. ${ }^{20}$ described the findings of nearly three dozen publications, asserting that "ultrasonography should be always the choice as an ideal support tool in medical education". Similarly, Lane et al. ${ }^{21}$ described the history of clinical ultrasound and ultrasound in medical education, citing fifty publications, concluding that "ultrasound in medical education is ingrained and will grow exponentially in the coming years" and calling for the allocation of further resources. Neither of these reviews approached the literature systematically or critically.

The body of literature focusing on ultrasound in medical education is growing, and many medical schools have begun to implement ultrasound-integrated curricula ${ }^{22}$. It is imperative to understand the rationale for the integration of ultrasound in UME, and the evidence supporting this trend, given the temporal and financial costs and uncertain 
clinical role in the hands of medical students ${ }^{23}$. In order to critically evaluate taken-forgranted assumptions about the benefits of ultrasound in UME, we used a systematic approach to explore the evidence found in academic publications.

\section{Methods}

We conducted our research in two phases. First, we identified dominant discursive rationales for the integration of ultrasound in UME by analyzing a large corpus of academic literature. Second, we critically and systematically reviewed the literature for empirical evidence in support of the identified discursive rationales. We followed the STORIES statement as a guide to the reporting of our systematic review of the evidence 24 .

We employed techniques from Foucauldian critical discourse analysis (CDA) to identify the dominant discursive rationales. Foucauldian CDA examines relationships between language, practices, and power to identify taken-for-granted assumptions about ideas that appear natural or inevitable and reveal the power relationships that support dominant ways of viewing the world ${ }^{25,26}$. Discursive rationales are statements of truth, the "surface manifestations" of discourse: "strongly articulated arguments about what is true/untrue, just/unjust, legitimate/illegitimate, permitted/forbidden in a given place or time ${ }^{\prime 27}$. The dominant discursive rationales were identified from an archive of academic publications related to ultrasound in medical education. This archive consisted 
of 403 texts published in academic journals between 1980 and 2016, located through searches in MEDLINE and Google Scholar (most recent update April 1, 2016) using the search terms 'ultrasound', 'ultrasonography', and 'medical education'. Relevant titles found in reference lists and citing articles identified using Google Scholar were also explored; 1395 articles were reviewed for relevance. We conducted an iterative textual analysis using Foucauldian CDA techniques focusing on frequently recurring truth statements, especially those that cited research evidence, to identify dominant discursive rationales for the integration of ultrasound in UME ${ }^{28-30}$.

We used these dominant discursive rationales as a framework to guide our review. We chose to frame our review in this way to achieve two ends: 1) in order to directly problematize dominant arguments as articulated by advocates; and 2) in order to approach the literature broadly as readers without content expertise in ultrasound education by allowing advocates' arguments to guide us.

For each rationale, we systematically searched the literature to identify supporting evidence. To locate relevant studies, we began by exploring the references cited by authors in support of their arguments. Next, we identified relevant articles in the archive described above. Finally, we searched the literature again using MEDLINE in order to identify any articles relevant to the rationales that might have otherwise been missed. The literature is highly heterogeneous, with few studies reporting on learning 
outcomes such as knowledge outcomes or behaviour/practice outcomes, and even fewer reporting on patient care outcomes. Because of this, our specific inclusion and exclusion criteria were relatively broad to allow for a large enough sample of literature to review; we included studies reporting on students' perceptions of curricular interventions, and comparative effectiveness using knowledge outcomes. Details regarding the standardized search strategies and the specific inclusion and exclusion criteria for searches associated with each rationale can be found in the associated appendix (Supplemental Table 1). Figure 1 illustrates the different sources of references used in the different parts of this paper. 


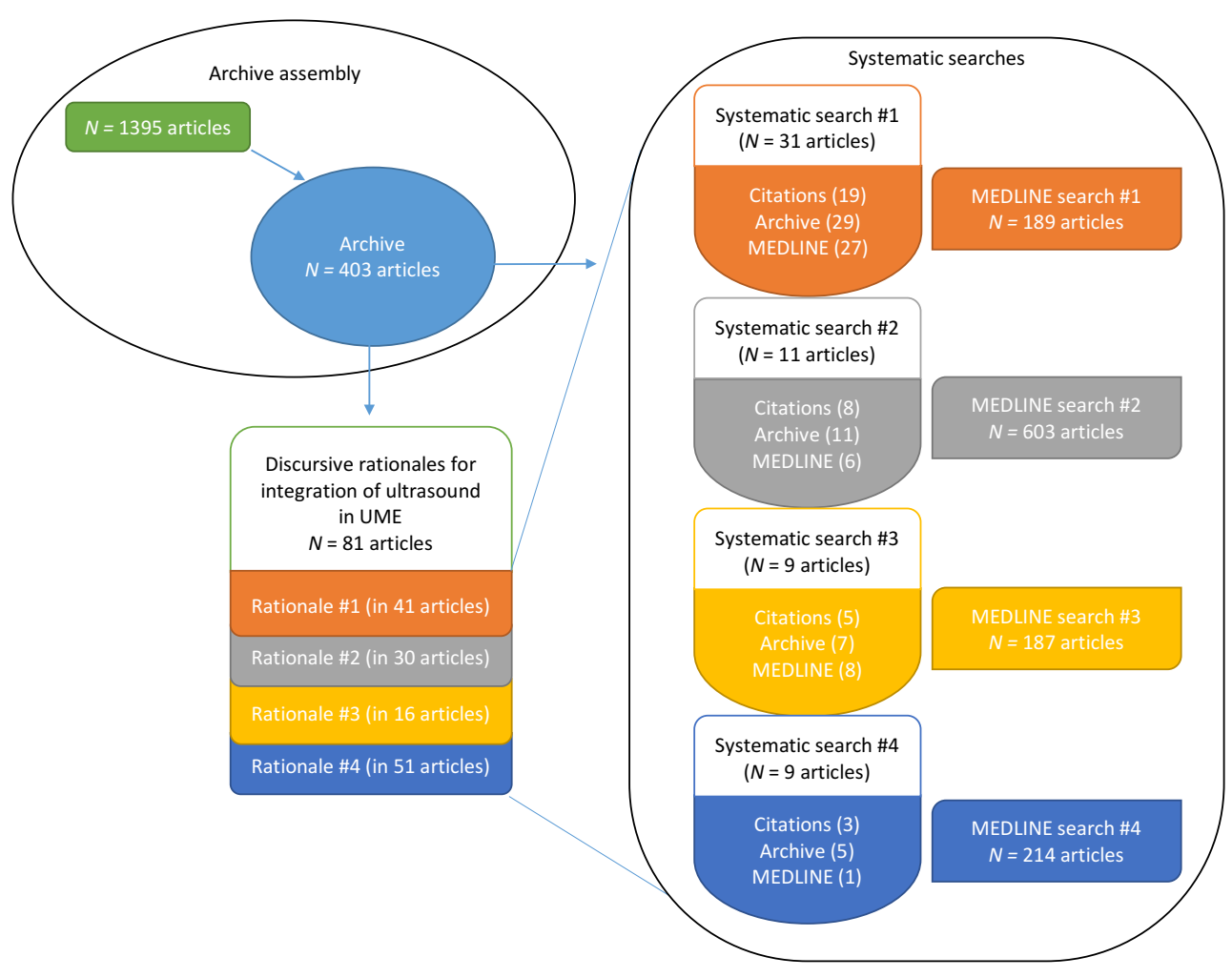

Figure 1. Schematic of the different sources and collections of references analyzed. In the first phase of research, an archive was assembled of academic publications related to ultrasound in medical education. From this archive, four discursive rationales were identified. These discursive rationales served as a framework to guide a systematic review of the evidence for the integration of ultrasound in undergraduate medical education (UME). Four separate systematic searches were conducted, with articles obtained from references cited by authors in support of their rationales, articles identified in the archive, and from systematic searches of MEDLINE.

The use of CDA techniques within a methodology for a critical literature review is

relatively novel. A recent article by Wall et al. ${ }^{31}$ describes the adaptation of

Habermasian CDA as a systematic review method that can help expose strongly- and

commonly-held assumptions within a research community. Our approach to data

extraction and qualitative data synthesis fits within the category of content analysis ${ }^{32}$

and focuses on the validity claims as described by Wall et al. ${ }^{31}$ and adapted from Cukier 
et al. ${ }^{33}$. Unlike these authors, because we are working in a different field, we first categorized publications by the outcomes (learning or otherwise) reported and summarized the relevant findings. In our synthesis, we concentrated on the 'truth' ("Is evidence and reasoning provided sufficient?") and 'sincerity' ("Is what is said consistent with how it is said?") claims within this CDA-oriented schema ${ }^{31,33}$. This data extraction and synthesis approach, to be clear, does not search for "conscious hegemonic participation"; it does not attempt to 'incriminate' authors as individual deceptive actors falsifying data due to conflicts of interest or ulterior motives ${ }^{31}$. We chose to focus on these validity claims to inform our understanding of the body of literature "to uncover unconscious hegemonic participation in academic research", critically focusing on dominant ideas and concepts that authors and research communities take for granted ${ }^{31}$. This critical review method is best served to answer our key questions about the availability of evidence for undergraduate ultrasound training while highlighting unquestioned assumptions within this domain of medical education research.

Our choice of approach in this review is necessarily informed by our individual and collective perspectives. Reflexively examining our own positions as readers of this literature and education researchers, we note first that none of us have conducted any prior research work related to POCUS. We are all physicians, three in medical subspecialties and one a primary care physician. As well, we are all involved in medical education research predominantly from a critical theoretical perspective. By adopting a 
critical method of systematic review rather than a traditional method employing statistical calculations and strenuously avoiding biases, we acknowledge the impact of our subjective positions, and how this figures into the interpretation of our results ${ }^{34}$.

Our research was not conducted on any human subjects; rather, our research materials exist in the public domain (academic publications). As such, and in consultation with the Office of Research Ethics at the University of Toronto, we did not seek ethical approval.

\section{Results}

Identifying discursive rationales

We identified 81 publications within our archive that contained rationales for the integration of ultrasound in UME published between 2005 and 2016. The recentness of publication is notable: 8 articles were published in the first quarter of 2016, 25 in 2015, and 20 in 2014, leaving only 28 published between 2005 and 2013. Four dominant discursive rationales emerged from our analysis. These are described below accompanied by a critical synthesis of the literature related to each rationale.

Rationale \#1: Ultrasound allows medical students to see inside a living body, leading to better understanding of anatomy

Because ultrasound can be used to 'see' inside the body, 'living anatomy' can supplement the traditional cadaver-based and cross-sectional anatomy teaching most 
medical students received. This is asserted to lead to a better understanding of anatomy. This rationale is found in 41 articles within the archive (e.g., $\left.{ }^{1,2,19,35,36,37}\right)$. A typical example of this rationale: "Ultrasound facilitates the learning of anatomy, aids in understanding the physiology and pathophysiology of numerous organs and systems" ${ }^{38}$.

We identified a total of 31 articles that informed this rationale. From the 40 different references cited by authors in support of their statements, 19 were relevant. We identified 29 articles as relevant from the 403 in our archive. Finally, our MEDLINE search yielded 189 articles, of which 27 were deemed relevant after review of titles and abstracts (see Supplemental Table 1 for search details). After removing duplicates, the 31 articles were categorized by outcomes. Positive student perceptions were reported as an outcome in 22 articles, and as the sole outcome in 10 articles. Improved ultrasound skills were reported in 8 articles. Increased self-reported knowledge was reported in 8 articles. Finally, increased anatomy knowledge, as measured by pre- and post-tests, was reported in 8 articles (Figure 2). 


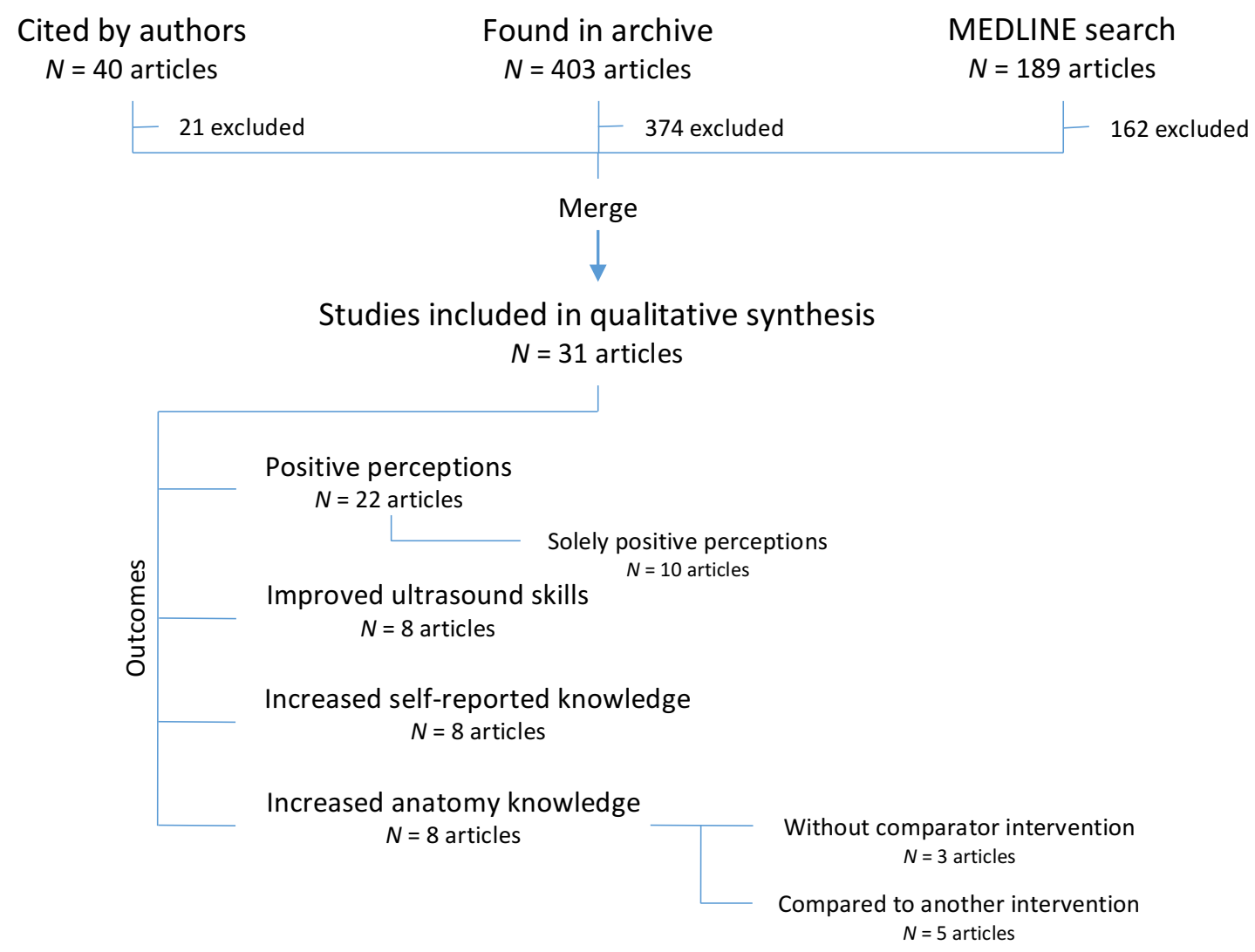

Figure 2. Derivation of study set for systematic review of evidence for Rationale \#1 (ultrasound improves anatomy learning), with division of articles by outcomes evaluated.

Definitive evidence of the effectiveness of ultrasound-based anatomy teaching would come from comparison to another method of instruction, evaluating knowledge outcomes. We identified 5 such articles, in which cadaver-based dissection was usually the comparator condition ${ }^{39-43}$. These were mostly brief interventions ( 30 minutes to 3 hours), excepting the report by Kondrashov et al. ${ }^{43}$, and all used multiple choice tests of anatomy knowledge, with Knobe et al. ${ }^{42}$ also measuring differential performance on a clinical skills examination. These 5 articles demonstrated no difference in knowledge 
gains as measured between ultrasound-based anatomy teaching and cadaver-based anatomy teaching. Knobe et al. ${ }^{42}$ demonstrated that arthroscopy-based teaching of shoulder anatomy led to improved post-test scores compared with ultrasound- or cadaver-based teaching.

We analysed the validity claims within the 31 articles selected for this review (Supplemental Table 2). We found a number of violations of truth claims, with overreliance of self-report methods, conflation of improved self-reported knowledge with improved knowledge, and confounding of improved ultrasound skills with improved anatomy knowledge. The literature prominently relies on positive perceptions as a measure of utility, which is an insubstantial reason for curriculum change, especially given its susceptibility to desirability bias ${ }^{44,45}$. We also found violations of sincerity claims, wherein connotative language is used to persuade the reader of interpretations beyond what is demonstrated. Inferences about the mechanism of the benefit of ultrasound (e.g., "an ultrasound-based lesson could be more effective because the professor could show what is happening inside the human body right in that moment" ${ }^{46}$ ) and the concreteness of conclusions (e.g., "ultrasound can augment the student's knowledge of anatomy acquired through traditional teaching methods while improving understanding of the clinical relevance of anatomical principles" ${ }^{44}$ ) stretch interpretations beyond the studies' designs. 
Rationale \#2: Ultrasound improves medical students' ability to learn physical examination techniques

By providing additional information while learning physical examination manoeuvres, ultrasound is claimed to be a useful teaching tool that will lead to improved physical exam technique. This rationale is found in 30 articles within the archive e.g., ${ }^{20,47,48-53}$. A typical phrasing: "Many advantages to early ultrasound education exist, including improvement in physical examination techniques" ${ }^{54}$.

We identified 11 articles that were relevant to this rationale. Only 8 of 33 papers cited by authors in support of this rationale were relevant. Some of the other articles cited by authors to support the claim that ultrasound training improves the learning of physical examination techniques in fact evaluated students' diagnostic accuracy with ultrasound ${ }^{55}$, or described undergraduate clinical ultrasound training ${ }^{56}$. The archive, which included those 8 articles, contributed 3 more, and no additional articles were discovered from our MEDLINE search (see Supplemental Table 1 for search details). The 11 studies were again categorized by the reported outcomes. Positive student perceptions were reported most commonly, as an outcome in 7 of the articles. Improved ultrasound skills were reported in 2 articles, and self-reported improvement in physical examination skills was reported as an outcome in 3 articles. Finally, physical examination skills were directly evaluated after ultrasound-augmented instruction in 6 articles (Figure 3). 


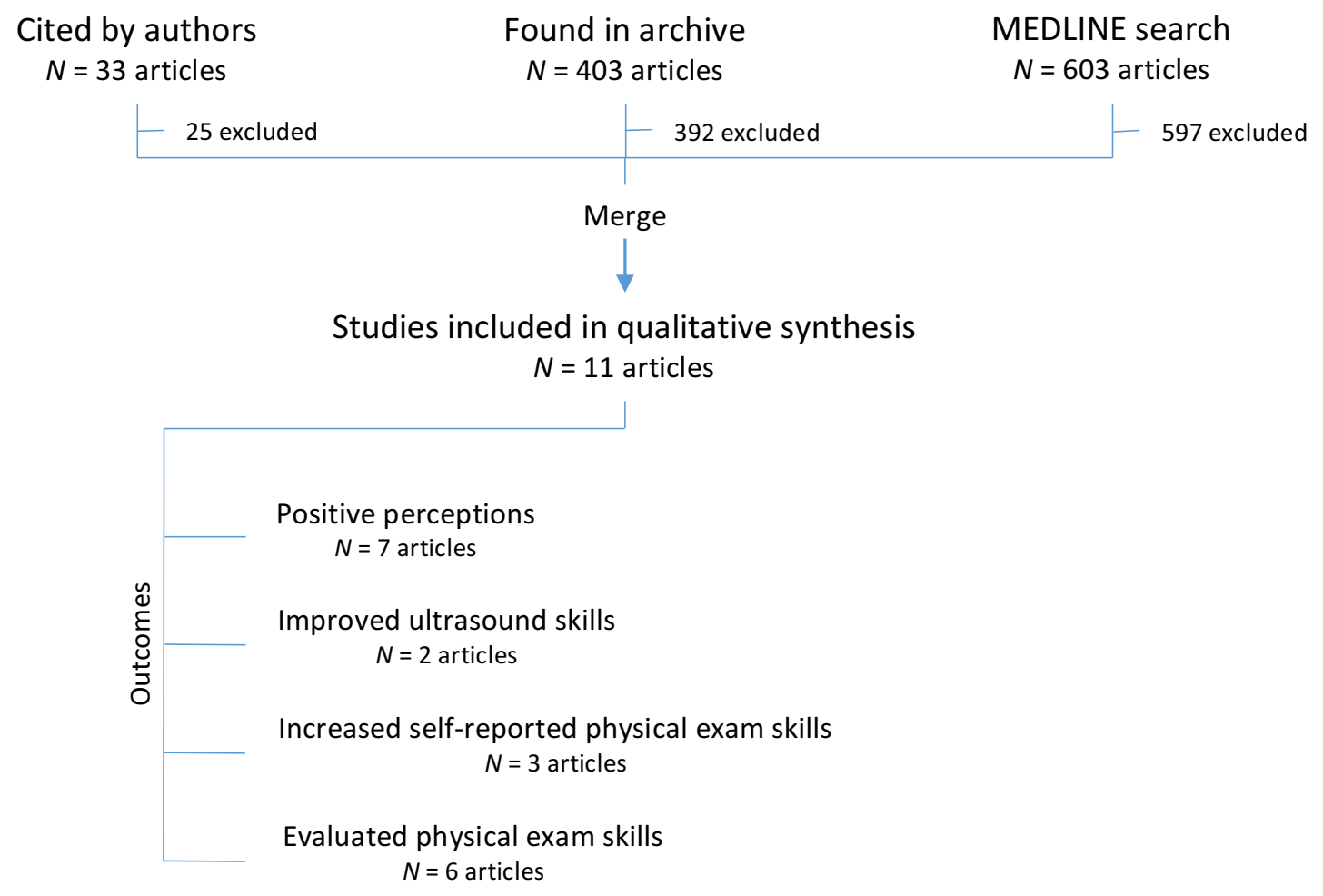

Figure 3. Derivation of study set for systematic review of evidence for Rationale \#2 (ultrasound improves physical examination learning), with division of articles by outcomes evaluated.

In these 6 studies, ultrasound was used as a teaching technique to visualize internal anatomy, after which physical examination skills were evaluated either directly as part of a pseudo-experimental study design, or via results on a structured clinical skills examination that was part of the students' standard evaluation ${ }^{57-62}$. Some of the methodological choices were unable to support inferences of benefit. For example, Am Dinh et al. ${ }^{58}$ compared standardized clinical skills examination results between two separate cohorts of students (one of which received an ultrasound-integrated clinical skills course); further, of the three 'organ systems' that the post-ultrasound cohort 
passed more successfully, one was 'blood pressure' and another was 'professionalism', which ultrasound could not have influenced. In another widely cited paper, Fodor et al. ${ }^{61}$ evaluated students' ability to identify multiple surface anatomy points, after some were provided ultrasound-augmented instruction. These surface anatomy points were seldom identified correctly by either group, but slightly more consistently, for some points, by students in the ultrasound condition. Notably, the students were tested on the same patient upon whom they had practised. Overall, the results were mixed and inconsistent, with positive findings in one study (improved accuracy estimating vertical liver span noted by Barloon et al. ${ }^{59}$ ) being imperfectly replicated (improved accuracy identifying the inferior liver margin, but not the superior shown by Fodor et al. ${ }^{61}$ ) or not replicated at all when re-examined (Butter et al. ${ }^{60}$ found no gains in accuracy estimating vertical liver span). One study reported a negative effect of ultrasound-assisted gastrointestinal anatomy learning on performance in a clinical skills examination when comparing different cohorts ${ }^{62}$.

Our analysis of validity claims within this body of literature again did not support some dominant conceptions within this research community (Supplemental Table 3). We found violations of truth claims including over-reliance on comparisons of different cohorts of students ${ }^{58}$ and continued reliance on self-reported gains ${ }^{63}$. The use of multiple measurements and statistical tests that may obscure the educational relevance of statistically significant findings is also problematic ${ }^{60,61}$. We found some violations of 
sincerity claims, including exaggerated interpretations of modest findings ${ }^{64}$, and the minimization of negative findings (e.g., casting doubt on the veracity of negative findings due to inherent flaws of comparing different cohorts, while ignoring how those flaws might affect interpretation of positive findings ${ }^{62}$ ).

Rationale \#3: Ultrasound improves medical students' diagnostic accuracy

The demonstration that students armed with ultrasound machines can 'out-diagnose' traditionally trained peers (or superiors) is asserted to be a compelling reason to ensure that medical students, incorrigibly poor diagnosticians, are taught this new skill. This rationale is found in 16 articles (e.g., ${ }^{65,66-69}$ ). A typical statement of this rationale: "several studies show that medical students and junior trainees using ultrasound are able to more reliably diagnose diseases than cardiologists and surgeons" ${ }^{19}$.

There were 5 relevant articles out of the 21 articles that were cited to support different phrasings of this rationale. We identified 7 relevant articles within our archive, and 8 articles were added from the 187 retrieved through our MEDLINE search (see Supplemental Table 1 for search details). The removal of duplicate references left 9 articles. All 9 articles compared medical students' diagnostic accuracy using POCUS with a standard diagnostic test. In 2 articles, medical students' accuracy using POCUS was also compared with the clinical examination conducted by an attending clinician, and in 
3 articles, authors evaluated the incremental benefit of POCUS when added to medical students' clinical examination (Figure 4).

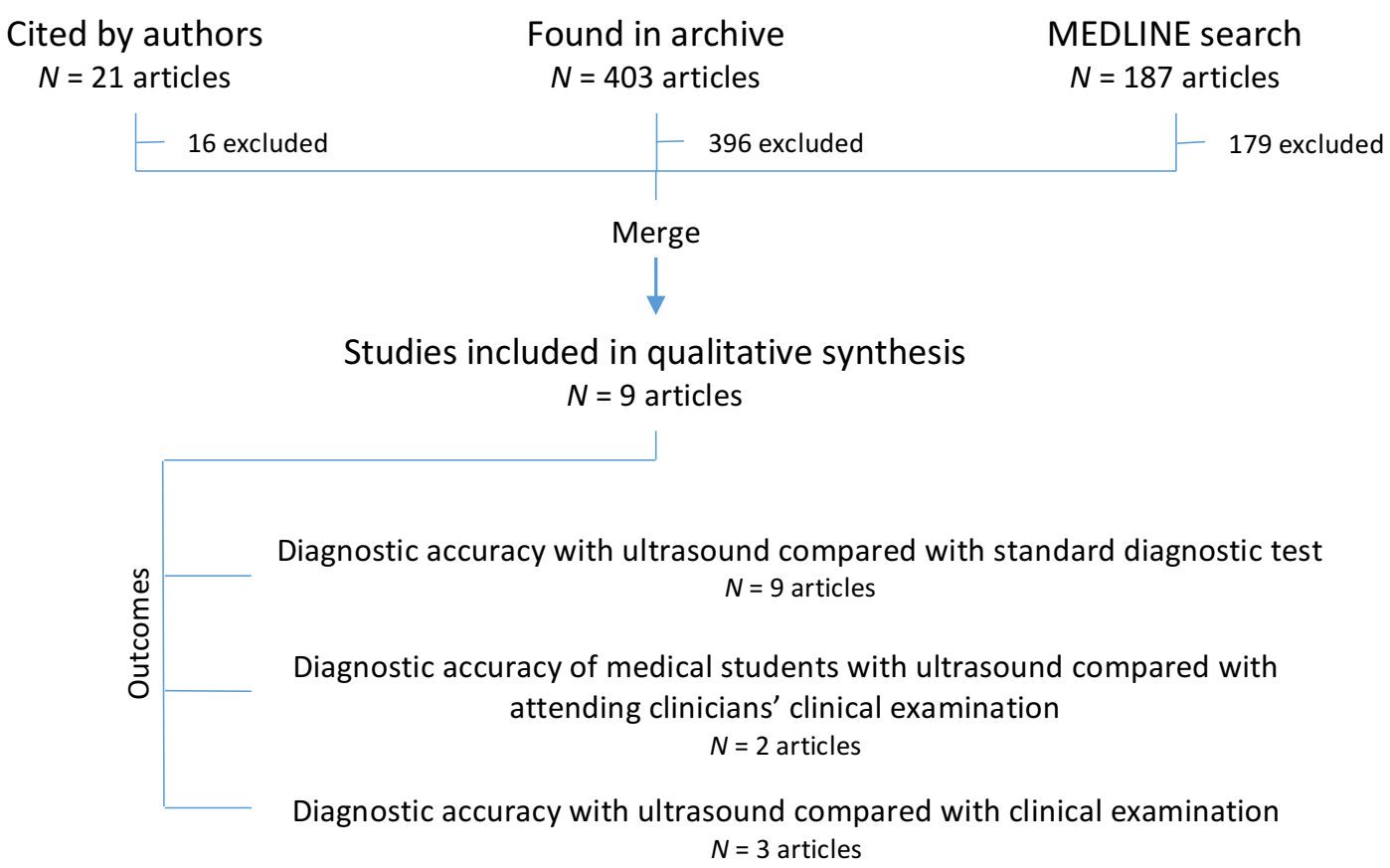

Figure 4. Derivation of study set for systematic review of evidence for Rationale \#3 (ultrasound improves students' diagnostic accuracy), with division of articles by outcomes evaluated.

In these 9 studies evaluating medical students' diagnostic accuracy with POCUS, relatively few students were trained and evaluated (a range of 2 to 30 subjects, median 10). Trained medical students performed POCUS with acceptably proficient accuracy compared to the diagnostic standard ${ }^{10,70-72}$. Medical students' diagnostic accuracy using ultrasound was found to be superior to that of the clinical evaluation of attending physicians in the 2 studies evaluating this outcome ${ }^{36,55}$. Results were mixed for the incremental benefit outcome; while one study reported significant improvement in 
diagnostic accuracy with the addition of POCUS ${ }^{73}$, for some diagnoses, diagnosis rates were not always improved by the addition of ultrasound (e.g., for mitral stenosis and regurgitation, students demonstrated poor performance with or without ultrasound in one study ${ }^{74}$; in another, medical students' ability to detect aortic valvular pathology did not improve with the use of ultrasound ${ }^{75}$ ).

We analyzed the validity claims of these 9 articles, identifying certain dominant conceptions (Supplemental Table 4). The most common violations of truth claims related to argumentation regarding the necessity of diagnostic ultrasound due to a deterioration of physical examination skills (e.g., "the interest and expertise of professionals in physical examination has declined substantially in recent decades" ${ }^{71}$; "The decline in physical examination skills during the past 2 decades is well documented and occurs at all levels of training" ${ }^{10}$ ) and reliance on results from small numbers of motivated subjects ${ }^{55,74}$. Claims of the decline in physical examination skills cite references that do not compare diagnostic accuracy over time. The main violation of sincerity claims relates to the consistent conclusion, where negative or equivocal findings were produced, that more extensive training in POCUS skills would rectify the lack of success with this tool ${ }^{74,75}$. While many concluded that future research would be required to determine the clinical utility of training students or residents in diagnostic ultrasound, some conclusions made a conceptual jump from improved diagnostic accuracy to improved clinical outcomes that were not demonstrated ${ }^{36,71}$. 
Rationale \#4: Undergraduate ultrasound training ensures a minimum ultrasound skill level, improving patient safety, and allowing for advanced training during residency Concerned that POCUS is currently being used without adequate training, and convinced that POCUS will inevitably become part of the core clinical skill set of modern physicians, many authors assert that ultrasound training must become part of the undergraduate medical curriculum. Training all medical students in ultrasound skills will purportedly lead to improved healthcare outcomes - initially of patients cared for by these newlyskilled medical students, but ultimately of all patients ${ }^{1}$. Related justifications include the following: 1) as an 'operator-dependent' imaging technology, ultrasound skills are difficult and time-consuming to learn; 2) clinicians in practice may find the acquisition of a new skill more difficult due to time constraints or different learning needs; and 3) post-graduate programs may not have the capacity to provide basic ultrasound training and also teach advanced applications. Variations of this rationale are found in 51 articles (e.g., ${ }^{3,5}, 22,23,35,46,53,56,76-81$ ). A typical expression: "Given its growing importance, it is time for the medical education community to debate whether the lack of ultrasound training is a disservice to future generations of medical students by depriving their opportunity to learn the clinical skills of the twenty-first century" ${ }^{82}$.

Through our systematic search process, we found 9 articles that were relevant to this rationale. In the majority of articles containing some formulation of this rationale, no 
references were cited to support the relevant statements; only 10 articles were cited, of which 3 were relevant. We identified 5 relevant articles within our archive, and 1 article was found to be relevant of the 214 retrieved through our MEDLINE search (see Supplemental Table 1 for search details). Of the 9 articles, 4 described changes in patient management following the use of POCUS by attending clinicians, 5 described similar changes with use of POCUS by post-graduate trainees, and 1 described improved procedural safety when medical students used POCUS (Figure 5).

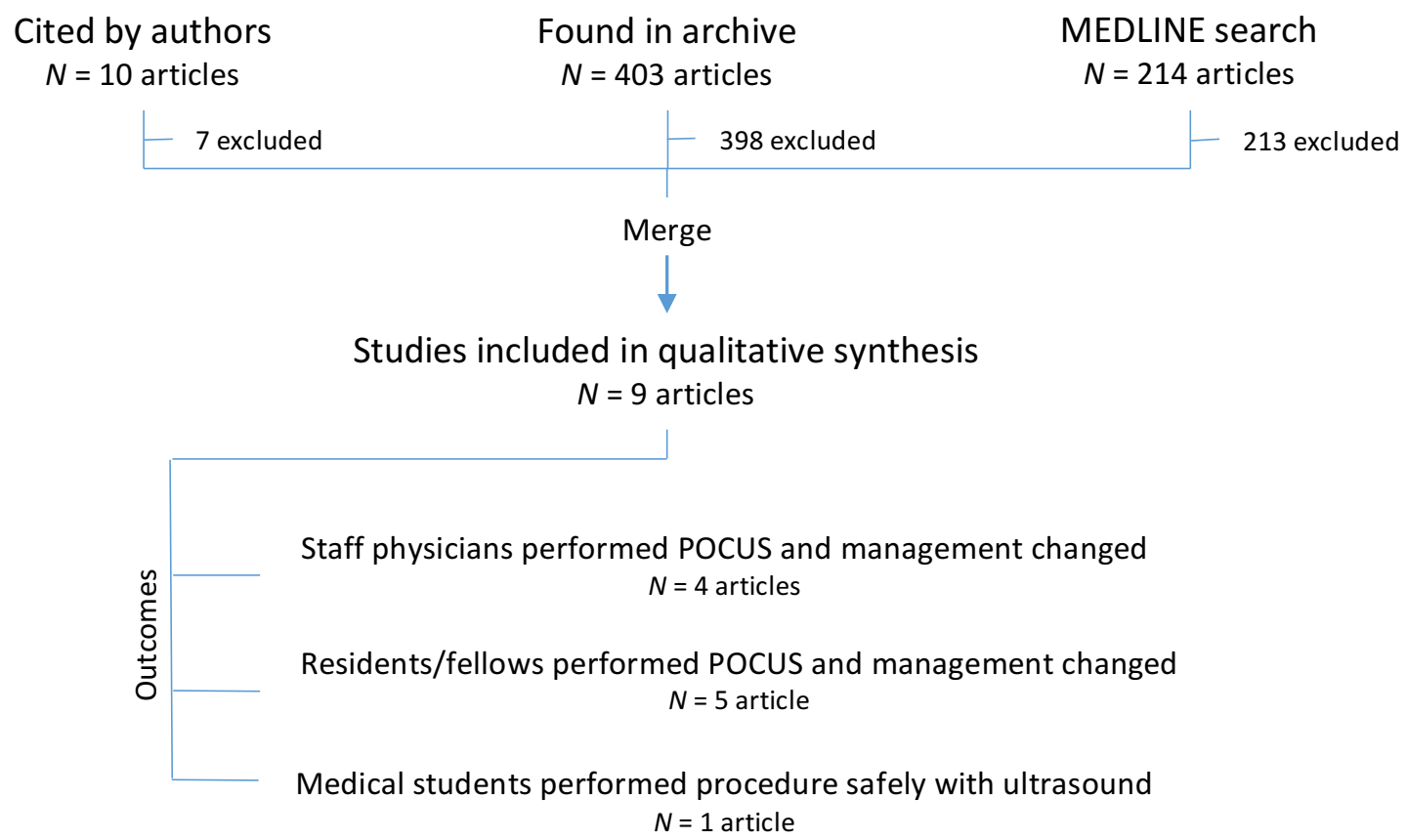

Figure 5. Derivation of study set for systematic review of evidence for Rationale \#4 (undergraduate ultrasound training improves patient safety), with division of articles by outcomes evaluated.

Among the studies reporting on the effects of training attending clinicians to perform POCUS, the application of POCUS was adjudicated to contribute to a change in 
management in $16-37 \%$ of cases in different clinical contexts ${ }^{83-86}$. Studies reported similar findings after training residents or fellows, with POCUS contributing to management changes in $16-40 \%$ of clinical applications ${ }^{84,87-90}$. Only one study evaluated any impact on patient-relevant outcomes of training medical students to perform POCUS, demonstrating improved safety of simulated central venous catheter placement using ultrasound ${ }^{91}$.

We analyzed the validity claims of the literature relevant to this rationale (Supplemental Table 5). The major truth claim violation involves the paucity of relevant evidence. As the rationale relates to undergraduate ultrasound training and the articles analyzed largely present findings related to post-graduate trainees or practicing clinicians, the translation of these findings to the undergraduate context remains untested. Furthermore, justifications regarding the inability of practicing clinicians to learn new skills and the lack of available room in post-graduate curricula are difficult to evaluate on the basis of any evidence beyond opinion. The studies analyzed rely on methodologies potentially subject to falsification (with self-collected data), and seldom question the relevance to patient care of improved pathology detection. In terms of sincerity claims, the most important conceptual issue relates to the inference frequently made between early learning and patient safety (e.g., "ultrasound technology is, of course, operator dependent and can be difficult to use, misleading at times, and prone to misinterpretations by the novice user. Consequently, early and comprehensive 
sonology education is a must" ${ }^{81}$ ). Finally, in concluding improved quality of care with the implementation of POCUS training, the implications of false negative results are seemingly ignored.

\section{Discussion}

We identified four dominant discursive rationales underpinning calls for the integration of ultrasound in UME which were used as a frame for a critical and systematic review. There is minimal evidence supporting assertions of the utility of ultrasound in teaching anatomy of physical examination skills. A small number of studies provide evidence to support the position that POCUS can improve students' diagnostic accuracy. However, there is a lack of empirical support for the rationale that links POCUS training in UME to improved patient safety. Analysis of validity claims revealed violations of truth claims related to methodological choices, as well as violations of sincerity claims related to hyperbolic and connotative language.

These discursive rationales are increasingly repeated by advocates of integrating ultrasound into UME, contributing to the legitimacy of the position. Two institutional bodies have issued policy statements in support of widespread ultrasound integration ${ }^{53}$ 92. Across North America and worldwide, medical schools are implementing ultrasoundintegrated curricula, encouraged by publication of 'ultrasound competencies' ${ }^{93}$. The incorporation of ultrasound in UME would require financial investment (for the 
purchase and maintenance of ultrasound machines), and temporal sacrifices (a reduction in the time available for other topics in the curriculum). Our results raise concerns that there is as yet insufficient evidence to support further integration of ultrasound in UME curricula.

Each discursive rationale relies on a logic of accepted truths, some of which may similarly be unsupported. For example, the second rationale relies on the premise that clinical examination skills are insufficiently accurate and are deteriorating over time. Skilled clinicians may in fact be more accurate with clinical examination than supposed ${ }^{94}$. Conversely, ultrasound may be less useful, less accurate, and may lead to more testing than otherwise assumed ${ }^{23}$. Furthermore, training medical students in ultrasound skills may lead to missed diagnoses due to "greater faith in "high tech' information" ${ }^{2}$. Thus, the incremental benefit of adding POCUS to a clinician's skill set may not be as large as seems implicit to proponents.

The other rationales rely on similar logics; the third rationale, emphasizing the improved diagnostic accuracy of ultrasound, ignores the possibility that increased diagnostic accuracy may not have a significant impact on patient outcomes ${ }^{95}$. Finally, evidence for the clinical use of diagnostic POCUS remains limited. Even the FAST protocol for identifying internal bleeding in patients who have suffered blunt trauma is not sufficiently sensitive to justify its use ${ }^{14}$. 
Medical education research is often conducted by interested and enthusiastic education researchers, such that there is a consistent bias towards the studied intervention ${ }^{96}$. These researchers participate in the 'unconscious hegemony' of the dominant discourses in their respective fields of academic research. This may hamper their ability to seek, or even perceive, potential unintended consequences of the educational intervention studied. Thus, we rarely have evidence of harms or shortcomings until after the implementation of curricular change; decisions are sometimes made based on a small volume of evidence.

From clinical medicine, cautionary tales of the broken promises of encouraging preliminary research are easy to find. Until 2002, observational data and scientific plausibility suggested a cardiovascular benefit to hormone replacement therapy for post-menopausal women, when a larger randomized controlled trial demonstrate opposite effects ${ }^{97}$. Relevant to the discussion of ultrasound as a more accurate diagnostic tool, pulmonary artery catheters were in widespread use in the care of critically ill patients before evidence emerged suggesting a lack of benefit and potential harms 98,99 .

Research questions in medical education research may not be as amenable to the methodologies used to determine the utility of clinical treatments or diagnostic 
techniques in these examples. However, there is an opportunity to learn from the ongoing experiences of schools where ultrasound has been integrated across the undergraduate curriculum ${ }^{3-5}$. Data regarding relevant knowledge outcomes, behaviour/practice outcomes, and even patient care outcomes could be collected prospectively.

\section{Limitations}

In conducting our review, we chose to frame our approach using the arguments put forth by advocates of ultrasound in UME as expressed in academic publications. Because of this, we have not systematically evaluated every possible rationale. A significant proportion of earlier literature on ultrasound in medical education was interested in delineating 'learning curves' for the acquisition of specific ultrasound skills in order to empirically determine the appropriate number of procedures to establish competence 100-102. The general consensus from this research concludes that a moderately large number of procedures (usually 50-75) must be performed to achieve proficiency ${ }^{103}$. We did not include this body of research in our systematic review, though it might inform the fourth rationale, in part because none of this evidence was cited by authors as reasons for early training of ultrasound skills, and in part because of the unclear relevance to UME (all of these studies included post-graduate or attending clinician participants). Furthermore, the studies evaluated in assessing the third rationale 
demonstrated reasonable accuracy after brief training periods; this would suggest that perhaps there is no need for lengthy training and a high volume of practice.

\section{Conclusions}

Using dominant discursive rationales as a framework, a systematic review of the literature demonstrates mostly absent or mixed evidence in support of rationales for the integration of ultrasound in UME. Our research problematizes the proliferation of ultrasound-integrated undergraduate curricula, and highlights some of the dominant concepts taken for granted by this research community which undermine the validity claims of the research within this field. 


\section{References}

[1] Hoppmann R, Blaivas M, Elbarbary M. Better medical education and health care through point-of-care ultrasound. Academic Medicine. 2012;87:134.

[2] Solomon SD, Saldana F. Point-of-care ultrasound in medical education--stop listening and look. New England Journal of Medicine. 2014;370:1083-1085.

[3] Bahner DP, Adkins EJ, Hughes D, Barrie M, Boulger CT, Royall NA. Integrated medical school ultrasound: development of an ultrasound vertical curriculum. Critical Ultrasound Journal. 2013;5:6.

[4] Hoppmann RA, Rao VV, Bell F, Poston MB, Howe DB, Riffle S, et al. The evolution of an integrated ultrasound curriculum (iUSC) for medical students: 9-year experience. Critical ultrasound journal. 2015;7:1-15.

[5] Rao S, van Holsbeeck L, Musial JL, Parker A, Bouffard JA, Bridge P, et al. A pilot study of comprehensive ultrasound education at the Wayne State University School of Medicine: a pioneer year review. Journal of Ultrasound in Medicine. 2008;27:745-749.

[6] Moore CL, Copel JA. Point-of-care ultrasonography. New England Journal of Medicine. 2011;364:749-757.

[7] Brass P, Hellmich M, Kolodziej L, Schick G, Smith AF. Ultrasound guidance versus anatomical landmarks for internal jugular vein catheterization. Cochrane Database Syst Rev. 2015;1. 
[8] Mercaldi CJ, Lanes SF. Ultrasound guidance decreases complications and improves the cost of care among patients undergoing thoracentesis and paracentesis. CHEST Journal. 2013;143:532-538.

[9] Tsang TS, Enriquez-Sarano M, Freeman WK, Barnes ME, Sinak LJ, Gersh BJ, et al., editors. Consecutive 1127 therapeutic echocardiographically guided pericardiocenteses: clinical profile, practice patterns, and outcomes spanning 21 years. Proceedings of the Mayo Clinic Proceedings. Elsevier; 2002.

[10] Decara JM, Kirkpatrick JN, Spencer KT, Ward RP, Kasza K, Furlong K, et al. Use of hand-carried ultrasound devices to augment the accuracy of medical student bedside cardiac diagnoses. Journal of the American Society of Echocardiography. 2005;18:257263.

[11] Ghane MR, Gharib MH, Ebrahimi A, Samimi K, Rezaee M, Rasouli HR, et al. Accuracy of Rapid Ultrasound in Shock (RUSH) Exam for Diagnosis of Shock in Critically III Patients. Trauma monthly. 2015;20.

[12] Lichtenstein DA, Meziere GA. Relevance of lung ultrasound in the diagnosis of acute respiratory failure. Chest Journal. 2008;134:117-125.

[13] Volpicelli G, Lamorte A, Tullio M, Cardinale L, Giraudo M, Stefanone V, et al. Point-of-care multiorgan ultrasonography for the evaluation of undifferentiated hypotension in the emergency department. Intensive care medicine. 2013;39:12901298. 
[14] Stengel D, Rademacher G, Ekkernkamp A, Güthoff C, Mutze S. Emergency ultrasound-based algorithms for diagnosing blunt abdominal trauma. status and date: Edited (no change to conclusions), published in. 2015.

[15] Kim JK, Rho J, Prasad V. Handheld Ultrasounds: Pocket Sized, but Pocket Ready? The American Journal of Medicine. 2013;126:845-846.

[16] Cook DA, West CP. Perspective: reconsidering the focus on "outcomes research" in medical education: a cautionary note. Academic Medicine. 2013;88:162-167.

[17] Dauphinee WD. Educators must consider patient outcomes when assessing the impact of clinical training. Medical education. 2012;46:13-20.

[18] Zendejas B, Brydges R, Wang AT, Cook DA. Patient outcomes in simulation-based medical education: a systematic review. Journal of general internal medicine.

2013;28:1078-1089.

[19] Chiem AT, Soucy Z, Am Dinh V, Chilstrom M, Gharahbaghian L, Shah V, et al. Integration of Ultrasound in Undergraduate Medical Education at the California Medical Schools A Discussion of Common Challenges and Strategies From the UMeCali Experience. Journal of Ultrasound in Medicine. 2016;35:221-233.

[20] Mircea PA, Badea R, Fodor D, Buzoianu AD. Using ultrasonography as a teaching support tool in undergraduate medical education - time to reach a decision. Medical Ultrasonography. 2012;14:211-216. 
[21] Lane N, Lahham S, Joseph L, Bahner D, Fox J. Ultrasound in medical education: listening to the echoes of the past to shape a vision for the future. European Journal of Trauma and Emergency Surgery. 2015:1-7.

[22] Am Dinh V, Fu JY, Lu S, Chiem A, Fox JC, Blaivas M. Integration of Ultrasound in Medical Education at United States Medical Schools A National Survey of Directors' Experiences. Journal of Ultrasound in Medicine. 2016;35:413-419.

[23] Mulvagh SL, Bhagra A, Nelson BP, Narula J. Handheld ultrasound devices and the training conundrum: how to get to "seeing is believing". Journal of the American Society of Echocardiography. 2014;27:310-313.

[24] Gordon M, Gibbs T. STORIES statement: Publication standards for healthcare education evidence synthesis. BMC Medicine. 2014;12:1-9.

[25] Hodges BD, Martimianakis MA, McNaughton N, Whitehead C. Medical education... meet Michel Foucault. Medical education. 2014;48:563-571.

[26] Foucault M. Power/knowledge: Selected interviews and other writings, 19721977 Pantheon; 1980.

[27] Hodges BD. The Shifting Discourses of Competence. In: Hodges BD, Lingard L, eds. The question of competence: reconsidering medical education in the twenty-first century. ILR Press, Ithaca (NY), 2013; 14-41.

[28] Haddara W, Lingard L. Are we all on the same page? A discourse analysis of interprofessional collaboration. Academic Medicine. 2013;88:1509-1515. 
[29] Martimianakis MA, Hafferty FW. The world as the new local clinic: A critical analysis of three discourses of global medical competency. Social Science \& Medicine. 2013;87:31-38.

[30] Whitehead C, Kuper A, Freeman R, Grundland B, Webster F. Compassionate care? A critical discourse analysis of accreditation standards. Medical Education. 2014;48:632-643.

[31] Wall J, Stahl BC, Salam A, editors. Critical Discourse Analysis as a Review Methodology: An Empirical Example. Association for Information Systems; 2015. [32] Snilstveit B, Oliver S, Vojtkova M. Narrative approaches to systematic review and synthesis of evidence for international development policy and practice. Journal of development effectiveness. 2012;4:409-429.

[33] Cukier W, Ngwenyama O, Bauer R, Middleton C. A critical analysis of media discourse on information technology: preliminary results of a proposed method for critical discourse analysis. Information Systems Journal. 2009;19:175-196.

[34] Gough D, Thomas J, Oliver S. Clarifying differences between review designs and methods. Systematic reviews. 2012;1:1.

[35] Bahner DP, Goldman E, Way D, Royall NA, Liu YT. The state of ultrasound education in U.S. medical schools: results of a national survey. Academic Medicine. 2014;89:1681-1686.

[36] Mouratev G, Howe D, Hoppmann R, Poston MB, Reid R, Varnadoe J, et al. Teaching medical students ultrasound to measure liver size: comparison with 
experienced clinicians using physical examination alone. Teaching \& Learning in Medicine. 2013;25:84-88.

[37] Pawlina W, Drake RL. New (or not-so-new) tricks for old dogs: Ultrasound imaging in anatomy laboratories. Anatomical sciences education. 2015;8:195-196.

[38] García de Casasola Sánchez G, Peinado DG, Gollarte AS, Aceituno EM, Vázquez IP, Macho JT. Teaching of clinical ultrasonography to undergraduates: Students as mentors. Revista Clínica Española. 2015;215:211-216.

[39] Canty DJ, Hayes JA, Story DA, Royse CF. Ultrasound simulator-assisted teaching of cardiac anatomy to preclinical anatomy students: A pilot randomized trial of a threehour learning exposure. Anatomical Sciences Education. 2015;8:21-30.

[40] Finn GM, Sawdon M, Griksaitis M. The additive effect of teaching undergraduate cardiac anatomy using cadavers and ultrasound echocardiography. European journal of anatomy. 2012;16:199-205.

[41] Griksaitis MJ, Sawdon MA, Finn GM. Ultrasound and cadaveric prosections as methods for teaching cardiac anatomy: a comparative study. Anatomical Sciences Education. 2012;5:20-26.

[42] Knobe M, Carow JB, Ruesseler M, Leu BM, Simon M, Beckers SK, et al. Arthroscopy or ultrasound in undergraduate anatomy education: a randomized crossover controlled trial. BMC Medical Education. 2012;12:85. 
[43] Kondrashov P, Johnson JC, Boehm K, Rice D, Kondrashova T. Impact of the clinical ultrasound elective course on retention of anatomical knowledge by second-year medical students in preparation for board exams. Clinical Anatomy. 2015;28:156-163. [44] Brown B, Adhikari S, Marx J, Lander L, Todd GL. Introduction of ultrasound into gross anatomy curriculum: perceptions of medical students. Journal of Emergency Medicine. 2012;43:1098-1102.

[45] Tshibwabwa ET, Groves HM. Integration of ultrasound in the education programme in anatomy. Medical Education. 2005;39:1148.

[46] Paganini M, Rubini A. Chest ultrasound integrated teaching of respiratory system physiology to medical students: a first experience. Advances in physiology education. 2015;39:129-130.

[47] Alsma J, Bosch F, Touw H, Tuinman P, Gelissen H, Lust E, et al. Ultrasound for internists: changing bedside examination. Neth J Med. 2015;73:98-99.

[48] Badea R. Medical education of students and residents-a new paradigm. Medical Ultrasonography. 2012;14:175-176.

[49] Bahner DP, Jasne A, Boore S, Mueller A, Cortez E. The ultrasound challenge: a novel approach to medical student ultrasound education. Journal of Ultrasound in Medicine. 2012;31:2013-2016.

[50] Gogalniceanu P, Sheena Y, Kashef E, Purkayastha S, Darzi A, Paraskeva P. Is Basic Emergency Ultrasound Training Feasible as Part of Standard Undergraduate Medical Education? Journal of Surgical Education. 2010;67:152-156. 
[51] Ma I, Wishart I, Kaminska M, McLaughlin K, Weeks S, Lautner D, et al. Medical educators' perspectives of teaching physical examinations using ultrasonography at the undergraduate level. Canadian Medical Education Journal. 2013;4:e59-e68.

[52] Palma JK. Successful Strategies for Integrating Bedside Ultrasound Into Undergraduate Medical Education. Military medicine. 2015;180:153-157.

[53] Soucy ZP, Mills LD. American Academy of Emergency Medicine Position Statement: Ultrasound Should Be Integrated into Undergraduate Medical Education Curriculum. Journal of Emergency Medicine. 2015.

[54] Cortez EJ, Boulger CT, Eastin T, Adkins EJ, Granitto E, Pollard K, et al. The Ultrasound Challenge 2.0 Introducing Interinstitutional Competition in Medical Student Ultrasound Education. Journal of Ultrasound in Medicine. 2014;33:2193-2196.

[55] Kobal SL, Trento L, Baharami S, Tolstrup K, Naqvi TZ, Cercek B, et al. Comparison of effectiveness of hand-carried ultrasound to bedside cardiovascular physical examination. American Journal of Cardiology. 2005;96:1002-1006.

[56] Angtuaco TL, Hopkins RH, DuBose TJ, Bursac Z, Angtuaco MJ, Ferris EJ. Sonographic physical diagnosis 101: teaching senior medical students basic ultrasound scanning skills using a compact ultrasound system. Ultrasound Quarterly. 2007;23:157160.

[57] Ahn JS, French AJ, Thiessen ME, Browne V, Deutchman M, Guiton G, et al. Using Ultrasound to Enhance Medical Students' Femoral Vascular Physical Examination Skills. Journal of Ultrasound in Medicine. 2015;34:1771-1776. 
[58] Am Dinh V, Frederick J, Bartos R, Shankel TM, Werner L. Effects of Ultrasound Implementation on Physical Examination Learning and Teaching During the First Year of Medical Education. Journal of Ultrasound in Medicine. 2015;34:43-50.

[59] Barloon TJ, Brown BP, Abu-Yousef MM, Ferguson KJ, Schweiger GD, Erkonen WE, et al. Teaching physical examination of the adult liver with use of real-time sonography. Academic Radiology. 1998;5:101-103.

[60] Butter J, Grant TH, Egan M, Kaye M, Wayne DB, Carrion-Carire V, et al. Does ultrasound training boost Year 1 medical student competence and confidence when learning abdominal examination? Medical Education. 2007;41:843-848.

[61] Fodor D, Badea R, Poanta L, Dumitrascu DL, Buzoianu AD, Mircea PA. The use of ultrasonography in learning clinical examination - a pilot study involving third year medical students. Medical Ultrasonography. 2012;14:177-181.

[62] Sweetman GM, Crawford G, Hird K, Fear MW. The benefits and limitations of using ultrasonography to supplement anatomical understanding. Anatomical Sciences Education. 2013;6:141-148.

[63] Shapiro RS, Ko PK, Jacobson S. A pilot project to study the use of ultrasonography for teaching physical examination to medical students. Computers in Biology \& Medicine. 2002;32:403-409.

[64] Afonso N, Amponsah D, Yang J, Mendez J, Bridge P, Hays G, et al. Adding new tools to the black bag--introduction of ultrasound into the physical diagnosis course. Journal of General Internal Medicine. 2010;25:1248-1252. 
[65] Am Dinh V, Dukes WS, Prigge J, Avila M. Ultrasound Integration in Undergraduate Medical Education: Comparison of Ultrasound Proficiency Between Trained and Untrained Medical Students. Journal of Ultrasound in Medicine. 2015;34:1819-1824.

[66] Bernard S, Richardson C, Hamann CR, Lee S, Am Dinh V. Head and Neck Ultrasound Education-A Multimodal Educational Approach in the Predoctoral Setting A Pilot Study. Journal of Ultrasound in Medicine. 2015;34:1437-1443.

[67] Blackstock U, Munson J, Szyld D. Bedside ultrasound curriculum for medical students: Report of a blended learning curriculum implementation and validation. Journal of Clinical Ultrasound. 2015;43:139-144.

[68] Cook T, Hunt P, Hoppman R. Emergency medicine leads the way for training medical students in clinician-based ultrasound: a radical paradigm shift in patient imaging. Academic Emergency Medicine. 2007;14:558-561.

[69] Kabaalioğlu A. Is Ultrasound out of Control? Medical ultrasonography. 2014;16:283-284.

[70] Andersen GN, Viset A, Mjolstad OC, Salvesen O, Dalen H, Haugen BO. Feasibility and accuracy of point-of-care pocket-size ultrasonography performed by medical students. BMC Medical Education. 2014;14:156.

[71] Garcia de Casasola Sanchez G, Torres Macho J, Casas Rojo JM, Cubo Romano P, Anton Santos JM, Villena Garrido V, et al. Abdominal ultrasound and medical education. Revista Clinica Española. 2014;214:131-136. 
[72] Parks AR, Verheul G, LeBlanc-Duchin D, Atkinson P. Effect of a point-of-care ultrasound protocol on the diagnostic performance of medical learners during simulated cardiorespiratory scenarios. CJEM Canadian Journal of Emergency Medical Care. 2015;17:263-269.

[73] Panoulas VF, Daigeler AL, Malaweera AS, Lota AS, Baskaran D, Rahman S, et al. Pocket-size hand-held cardiac ultrasound as an adjunct to clinical examination in the hands of medical students and junior doctors. European heart journal cardiovascular Imaging. 2013;14:323-330.

[74] Shmueli H, Burstein Y, Sagy I, Perry ZH, Ilia R, Henkin Y, et al. Briefly trained medical students can effectively identify rheumatic mitral valve injury using a handcarried ultrasound. Echocardiography. 2013;30:621-626.

[75] Stokke TM, Ruddox V, Sarvari SI, Otterstad JE, Aune E, Edvardsen T. Brief Group Training of Medical Students in Focused Cardiac Ultrasound May Improve Diagnostic Accuracy of Physical Examination. Journal of the American Society of Echocardiography. 2014;27:1238-1246.

[76] Arger PH, Schultz SM, Sehgal CM, Cary TW, Aronchick J. Teaching medical students diagnostic sonography. Journal of Ultrasound in Medicine. 2005;24:1365-1369.

[77] Cawthorn TR, Nickel C, O'Reilly M, Kafka H, Tam JW, Jackson LC, et al. Development and evaluation of methodologies for teaching focused cardiac ultrasound skills to medical students. Journal of the American Society of Echocardiography. 2014;27:302-309. 
[78] Hamza A, Solomayer E-F, Takacs Z, Juhasz-Boes I, Joukhadar R, Radosa J, et al. Introduction of basic obstetrical ultrasound screening in undergraduate medical education. Archives of gynecology and obstetrics. 2016:1-7.

[79] Ho AM-H, Critchley LA, Leung JY, Kan PK, Au SS, Ng SK, et al. Introducing FinalYear Medical Students to Pocket-Sized Ultrasound Imaging: Teaching Transthoracic Echocardiography on a 2-Week Anesthesia Rotation. Teaching \& Learning in Medicine. 2015;27:307-313.

[80] Jeppesen KM, Bahner DP. Teaching bedside sonography using peer mentoring: a prospective randomized trial. Journal of Ultrasound in Medicine. 2012;31:455-459.

[81] Stawicki SP, Bahner DP. Modern sonology and the bedside practitioner: evolution of ultrasound from curious novelty to essential clinical tool. European Journal of Trauma and Emergency Surgery. 2015;41:457-460.

[82] Wong I, Jayatilleke T, Kendall R, Atkinson P. Feasibility of a focused ultrasound training programme for medical undergraduate students. The clinical teacher. 2011;8:37.

[83] Blaivas M, Kuhn W, Reynolds B, Brannam L. Change in differential diagnosis and patient management with the use of portable ultrasound in a remote setting. Wilderness \& environmental medicine. 2005;16:38-41.

[84] Conlon TW, Himebauch AS, Fitzgerald JC, Chen AE, Dean AJ, Panebianco N, et al. Implementation of a Pediatric Critical Care Focused Bedside Ultrasound Training Program in a Large Academic PICU*. Pediatric Critical Care Medicine. 2015;16:219-226. 
[85] Kimura BJ, Shaw DJ, Agan DL, Amundson SA, Ping AC, DeMaria AN. Value of a cardiovascular limited ultrasound examination using a hand-carried ultrasound device on clinical management in an outpatient medical clinic. The American journal of cardiology. 2007;100:321-325.

[86] Manasia AR, Nagaraj HM, Kodali RB, Croft LB, Oropello JM, Kohli-Seth R, et al. Feasibility and potential clinical utility of goal-directed transthoracic echocardiography performed by noncardiologist intensivists using a small hand-carried device (SonoHeart) in critically ill patients. Journal of cardiothoracic and vascular anesthesia. 2005;19:155159.

[87] Andersen GN, Graven T, Skjetne K, Mjølstad OC, Kleinau JO, Olsen $\varnothing$, et al. Diagnostic Influence of Routine Point-of-Care Pocket-size Ultrasound Examinations Performed by Medical Residents. Journal of Ultrasound in Medicine. 2015;34:627-636. [88] Croft LB, Duvall WL, Goldman ME. A pilot study of the clinical impact of handcarried cardiac ultrasound in the medical clinic. Echocardiography. 2006;23:439-446. [89] Killu K, Coba V, Mendez M, Reddy S, Adrzejewski T, Huang Y, et al. Model Pointof-Care Ultrasound Curriculum in an Intensive Care Unit Fellowship Program and Its Impact on Patient Management. Critical care research and practice. 2014;2014.

[90] Ramsingh D, Rinehart J, Kain Z, Strom S, Canales C, Alexander B, et al. Impact assessment of perioperative point-of-care ultrasound training on anesthesiology residents. The Journal of the American Society of Anesthesiologists. 2015;123:670-682. 
[91] Griswold-Theodorson S, Hannan H, Handly N, Pugh B, Fojtik J, Saks M, et al. Improving patient safety with ultrasonography guidance during internal jugular central venous catheter placement by novice practitioners. Simulation in Healthcare: The Journal of The Society for Medical Simulation. 2009;4:212-216.

[92] Cantisani V, Dietrich C, Badea R, Dudea S, Prosch H, Cerezo E, et al. EFSUMB statement on medical student education in ultrasound [short version]. Ultraschall in der Medizin-European Journal of Ultrasound. 2016;37:100-102.

[93] Am Dinh V, Lakoff D, Hess J, Bahner DP, Hoppmann R, Blaivas M, et al. Medical Student Core Clinical Ultrasound Milestones A Consensus Among Directors in the United States. Journal of Ultrasound in Medicine. 2016:15.07080.

[94] Bloch A, Crittin J, Jaussi A. Should functional cardiac murmurs be diagnosed by auscultation or by Doppler echocardiography? Clinical cardiology. 2001;24:767-769. [95] Prasad V, Kim J, Rho J. The Reply. The American Journal of Medicine. 2014;127:e21-e21.

[96] Colliver JA, Kucera K, Verhulst SJ. Meta-analysis of quasi-experimental research: are systematic narrative reviews indicated? Medical education. 2008;42:858-865. [97] Investigators WGftWsHI. Risks and benefits of estrogen plus progestin in healthy postmenopausal women: principal results from the Women's Health Initiative randomized controlled trial. Jama. 2002;288:321-333.

[98] Marik PE. Obituary: pulmonary artery catheter 1970 to 2013. Annals of intensive care. 2013;3:1. 
[99] Rajaram SS, Desai NK, Kalra A, Gajera M, Cavanaugh SK, Brampton W, et al.

Pulmonary artery catheters for adult patients in intensive care. Cochrane Database Syst Rev. 2013;2.

[100] Gaspari RJ, Dickman E, Blehar D. Learning curve of bedside ultrasound of the gallbladder. Journal of Emergency Medicine. 2009;37:51-56.

[101] Jang T, Aubin C, Naunheim R. Minimum training for right upper quadrant ultrasonography. American Journal of Emergency Medicine. 2004;22:439-443.

[102] Smith RS, Kern SJ, Fry WR, Helmer SD. Institutional learning curve of surgeonperformed trauma ultrasound. Archives of Surgery. 1998;133:530-535; discussion 535536.

[103] Blehar DJ, Barton B, Gaspari RJ. Learning Curves in Emergency Ultrasound Education. Academic Emergency Medicine. 2015;22:574-582. 